\title{
IMAGINÁRIO CARNAVALESCO, RISO E UTOPIA NOS FABLIAUX MEDIEVAIS
}

\author{
José Rivair Macedo \\ Departamento de História - UFRG
}

RESUMO: O presente artigo pretende examinar alguns aspectos das imagens do Carnaval e da Quaresma em textos cômicos dos séculos XIII e XIV, verificando as similaridades e divergências na interpretaçāo do tema do combate entre o Carnaval e a Quaresma nos fabliaux e no Libro de Buen Amor, de Arciprestre de Hita.

ABSTRACT: This article examines some aspects of the images of Carnival and Lent in comical texts which date from the thirteenth and fourteenth centuries, establishing the similarities and differences in the interpretation of the theme of combat betwcen Carnival and Lent in the fabliaux and in Livro de Buen Amor, of Arciprestre de Hita.

PALAVRAS-CHAVE: Imaginário, Camaval, utopia, fabliaux, cultura popular.

KEY-WORDS: Imaginary, Carnival, utopia, fabliaux, popular culture.

Ao contrário do que costumamos supor, os registros de manifestaçōes utópicas foram constantes e excepcionalmente ricos na Europa medieval. A variedade de formas e sentidos do fenômeno utópico no conjunto da Cristandade Ocidental tem constituído excelente objeto de estudo de medievalistas, entre os quais o brasileiro Hilário Franco Júnior (FRANCO JR., 1992). A riqueza de dados e as perspectivas de abordagem do problema apresentam inúmeras questōes $\mathrm{e}$ direcionamentos de pesquisa aos historiadores.

Neste sentido, gostaríamos de apresentar algumas reflexões a respeito da relação entre riso $\mathrm{e} u$ utopia. Até que ponto, perguntamo-nos, as utopias me- dievais podem ser observadas nas manifestaçōes do riso e do cômico? Qual a dimensão do espaço utópico em obras literárias reveladoras de um imaginário carnavalesco, imbuídas de caráter lúdico e jocoso?

Tomemos como referencial de análise um poema herói-cômico do final do século XIII, de autoria anônima, chamado La Bataille de Caresme et de Charnage. $O$ texto contém 574 versos, cujos motivos literários, rima e versificação assemelham-se aos das canções de gesta. $O$ assunto, todavia, diverge bastantc daquele da poesia heróica. O tema narrado, como veremos, diz respeito a um combate bizarro, motivo pelo qual os especialistas em literatura medie- 
val acostumaram-se a integrar este texto paródico no gênero dos fabliaux.

O tema do fabliau aparece uma vez mais no Libro de Buen Amor, escrito em meados do século XIV pelo clérigo ibérico Arciprestre de Hita. Neste longo poema alegórico, sensual e satírico, Arciprestre de Hita encontra espaço de sobra para ridicularizar os excessos mundanos, os padres voluptuosos e as mulheres afoitas. Porém uma das mais curiosas passagens do Libro é dedicada à descrição De la Pelea que ovo Don Carnal con la Quaresma.

Apcsar das particularidades da língua, do estilo e diversificação no desenvolvimento do assunto, os dois textos descrevem os pormenores de um combate imaginário $\mathrm{c}$ burlesco, travado entre o Carnaval $\mathrm{e}$ a Quaresma.

No fabliau, a bufonaria tem início quando o nobre Caresme ofende o nāo menos poderoso senhor Charnage. Ambos preparam-se para a guerra. Vassalos, amigos e aliados enfilciram-se de ambos os lados. Um exército de animais aquáticos organiza-se para defender Caresme. Outro exército, integrado por animais terrestres, assim como suculentas iguarias comestiveis, prepara-se para socorrer Charnage.

$\mathrm{Na}$ batalha gastronômica, os dois principais protagonistas enfrentam-se num corpo a corpo. Depois, é a "carnificina" generalizada. No final do terrível combate, Noel (Natal), terceiro personagem alegórico, surge em cena para reforçar os efetivos das hostes de Charnage. Dando-se por vencido, Caresme propóe a paz, submetendo-se a um exílio temporário, para ser rompido apenas durante certos dias de cada ano.

Ao apresentar o mesmo episódio no Libro de Buen Amor, Arciprestre de Hita adiciona dados novos, dando-lhes outro sentido. Don Carnal é surpreendido por Dona Quaresma à meia-noite, durante o sono. É vencido, aprisionado e obrigado a fazer penitência, submetendo-se a um severo jejum. Depois de algum tempo, consegue escapar da prisão e reunir aliados, impondo em seguida seus desejos ao adver- sário. Os animais aquáticos tinham retornado para o seu habitat natural e não puderam socorrer Quaresma. No final, não houve outra alternativa para esta a nāo ser partir em exílio, reconhecendo a vitória de Carnal.

Considerando os elementos gerais presentes em ambos os textos, percebe-se de imediato que o tema tratado esteve intrinsecamente ligado ao universo da cultura cômica popular medieval. Os aspectos gerais relacionados a csta questăo foram analisados com excepcional desenvoltura pelo crítico literário russo Mikhail Bakhtin, em seu célebre estudo a respeito de Rabelais (BAKHTIN, 1987). Em primeiro lugar, parece cvidente a presença do que Bakhtin conceituou como Rcalismo Grotesco, isto é, o rebaixamento paródico e satírico de um assunto extraído da cultura séria c oficial, visando a comicidade e o riso. $\mathrm{O}$ vocabulário livre, jocoso, o tom de brincadeira, de ironia e além do mais, o espírito carnavalesco subjacente aos versos dos textos assinalados, concorrem substancialmente para esta caracterizaçāo.

A personificação do Carnaval e da Quaresma, na verdade, ia além da mera representaçāo literária. Num conhecido trabalho sobre o Carnaval, o etnólogo basco Julio Caro Baroja recolheu inúmeros testemunhos da tradição folclórica espanhola que nos dão conta de curiosos rituais burlescos rcalizados por ocasiāo dos festejos carnavalescos. Entre estes, merece destaque o julgamento, condenação e morte de Saint Pansard, Saint Antruejo ou San Tragantón, de Meco, Pau Pi, Peirote ou Pero-palo, nomes locais atribuídos ao Carnaval. O mesmo, aliás, $\mathrm{cm}$ momento diverso, ocorria com a Quaresma, chamada de S'Avia Corema ou Jaya Serrada e representada por uma vetha enorme feita de papel. No final da Quaresma, ela era queimada ou destruída pelos jovens, crianças e foliōes das aldeias (BAROJA, 1979).

A melhor representaçāo plástica do tema, todavia, aparece na pintura Le Combat entre Carnaval et Caresme, criada em 1559 pelo célebre pintor flamen- 
go Peter Bruegel. Nela pode-se notar, em cores muito vivas, a força do antigo motivo de inspiração popular que estamos procurando examinar (BRUEGEL, 1978, prancha 10 ).

No lado esquerdo do quadro, Bruegel pintou pessoas preparando comida, algumas jogando dados e outras tocando instrumentos musicais. É o lado da festa, do Carnaval. A figura principal desta cena é um homem obeso sentado numa pipa de vinho. Ele usa um barrete frígio, ornamento tradicional dos "Youcos". Acima da cabeça, tem um suculento prato. $\mathrm{Na}$ mão direita empunha um longo espeto com algumas aves assadas. $O$ estribo do cavalo alegórico é um caldeirāo. $O$ "animal" é empurrado por um foliāo.

No lado oposto do quadro, a situação é bem outra. As pessoas representadas aparentam contrição. Algumas dão esmolas aos doentes, cegos, paralíticos. Mutheres preparam peixes perto de um poço. Quase todos vestem roupas escuras. É o lado da Quaresma. Dominando a cena, um monge e uma mulher arrastam um carro de madeira. Sobre o veículo há uma velha magra, doentia e feia. Tem um cesto sobre a cabeça. Na mão esquerda segura um feixe de ervas; com a direita, empunha uma longa e fina pá de madeira, em cuja ponta repousam dois peixes. Quaresma usa a pá como arma para combater o espeto do "cavaleiro" da pipa. No fundo do quadro, um bobo, vestido de verde, amarelo e vermelho, caminha com uma tocha na mão, afastando-se da cena do combate (GAIGNEBET, 1972, pp. 313-345; BRION, 1936, p. 42).

Assim, percebemos que os textos, imagens ou os rituais festivos carnavalescos brincavam com uma instituiçāo basilar da doutrina cristã: a prática da quaresma.

Instituída no Ocidente pelo menos desde o século IV, apesar de modificações ao longo do tempo, a Quaresma constituiu e de certo modo continua a constituir importante sustentáculo da moral cristã. Os quarenta dias que antecediam à Páscoa representavam um período de continência e abstinência para os cristāos; uma época de ascese e de disciplina. Neste período anual o jejum diário e a privação de alimentos de origem animal (salvo os peixes) deveria levar os fiéis a uma espécie de purgação espiritual, preparando-os para a rememoração do martírio, morte e ascensáo de Cristo (VACANDARD, 1910a, pp. 1720-1731.).

Os preceitos eclesiásticos afetavam muito mais que o estômago. A doutrina prescreve várias obrigações na Quaresma. O contato carnal deveria ser tão evitado quanto a ingerência de carne vermelha. Exigia-se dos esposos contençăo nas relações sexuais. As festas, inclusive as dos santos, as diversōes, núpcias, jogos, representaçōes teatrais, processos criminais e outras atividades năo poderiam ser realizados. A observância da regra moral integrava exercícios de caridade e a freqüência constante aos ofícios religiosos. Em suma, neste período todos os fiéis deveriam submeter-se a uma série de penitências, práticas piedosas e purificação espiritual via mortificaçāo do corpo (VACANDARD, 1925b, p. 2153).

$\mathrm{O}$ autor desconhecido do conto cômico $L a$ Bataille de Caresme et de Charnage atribuiu qualidades e defeitos pessoais aos dois protagonistas do combate bufo. Charnage é grande barão no reino dos Francos: possui terras, bens e muitos amigos; é valente e corajoso, desfruta do amor e do respeito geral. Quanto ao adversário, também é rico e poderoso: tem inúmeras propriedades, abadias; é senhor do mar e um bom pedaço de terra integra o seu domínio.

Os dois personagens parecem simbolizar categorias específicas da elite nobre. Charnage, a julgar pelas qualidades atribuídas, identifica-se com o aristocrata laico, com o nobre guerreiro. Caresme, pelas posses assinaladas, representa o poder da Igreja. Seu domínio por excelência é o mar e seus guerreiros são os peixes. Ora, a simbologia dos peixes estava intimamente ligada ao plano religioso.

No antigo Oriente, os peixes representavam o sacrifício e a ligação do Céu com a Terra. Pela abundância dos ovos, tornaram-se símbolos fálicos e de ferti- 
lidade (CIRLOT, 1984, p. 454). Os cristāos, já nos primórdios de sua história, associaram-nos à figura de Cristo, inscrevendo-os abundantemente em obras de caráter iconográfico. Como símbolo cristológico, os peixes remetem à idéia do batismo e da eucaristia: nascido espiritualmente da água do batismo, o cristão ć comparado a um pequeno peixe. Da palavra grega utilizada para se referir a este animal - IKHTUS os excgetas encontraram as letras iniciais que indicam a divindade de Cristo: lêsous Khristos Theou Uius Sôtêr (FERGUSON, 1961, p. 18; REAU, 1957, p. 29; CHEVALIER, 1974, p. 43).

As hostes recrutadas por Caresme provém das águas: baleias, salmōes, enguias $\mathrm{c}$ arenques integram o cxército dos "Cavalciros do mar". Pelo lado de Charnage, são os animais terrestres - quadrúpedes $\mathrm{e}$ bípedes - que forneccm o contingente de guerreiros. Dizemos fornecem, pois não são exatamente os animais que combatcm e sim os alimentos preparados com sua carne. Assim, nas fileiras carnavalcscas agrupam-se os guerreiros Carne de Porco, Tripas de Porco e de Carneiro, Toucinho de Porco e de Cervo, Carne de Boi, Grou, Pavão Assado, Pescoço de Cisne, Carne de Galinha, Salsicha, Tortas, Mostarda, Queijo e outras iguarias mais. Equipados com elmos, lanças, espadas e escudos, seguem Charnage, que empunha uma bandeira de queijos e monta um cervo selvagem.

Na guerra mortal que se desenrola, é Caresme quem leva a pior:

La batailte fu moult espesse,

Dure et orible et felonesse.

Quaresme i reçut grant domage

De sa gent et de son lingnage,

Et Charnage qui moult fu fier

Retret sa gent por l'anuitier (vv. 493-497)

Por trás da cortina de seriedade tecida pelos representantes da cultura oficial, um quadro diferente tomou forma entre os séculos XII-XIII. Parte substancial da construção da imaginação carnavalesca devemos aos jograis, aos joculatores, grupo heterogêneo, integrado por criadores, narradores ou verbalizadores da poesia. Na categoria, não faltaram músicos, malabaristas, acrobatas, atores mambembes, frequientadores dos castelos, das portas das igrejas, das feiras, gestas e torneios. A eles se deve a elaboração de uma visāo de mundo inspirada pela massa de anônimos, em geral ausente ou submersa no discurso eclesiástico. O jogral era, antes de tudo, um disseminador de idéias e do que hoje chamamos arte, sobrevivendo com a venda do talento c com o reconhecimento do público ao qual se dirigia (FARAL, 1987, p. 2; ZUMTHOR, 1993).

A posição da lgrcja em relaçăo a estes mercadores da palavra, ilustra suficientemente bem o significado das obras que criavam. Em geral, ela condenou as atividades dos saltimbancos, considerando-as pe. rigosas e excitadoras do pecado. Os atores mambembes e os jograis de corte, vistos como parasitas, errantes e caluniadores, não escapavam das censuras dos prelados. No caso dos músicos, o peso da reprovação incidia apenas sobre os freqüentadores de bailes e tavernas. Os jograis que se dedicavam a cantar os fcitos dos heróis ou a vida dos santos nāo sofriam qualquer tipo de condenação (LE GOFF, 1980, p. 89).

Por outro lado, os representantes da Igreja procuraram reabilitar.a imagem dos amadores do mundo: São Francisco de Assis gostava de ser chamado o "Jogral de Cristo" e os Franciscanos, de "Jograis de Deus". Um dos Miracles de Notre Dame, datado de 1268, chamado Del Tumbeor Nostre Dame, conta o caso de um jogral desgostoso da vida mundana que, abandonando os velhos hábitos devassos, entra num convento e passa a dignificar a Virgem Maria. Como não sabe orar nem honrá-la de outra maneira, dança em sua homenagem, sendo abençoado (KUNSTMANN, 1981, pp. 143-178).

Parece, todavia, que a imagem do jogral saltimbanco jamais conseguiu ser completamente dissoci- 
ada do submundo. Um fabliau muito pouco exemplar de um anônimo do século XIII, chamado De Saint Pierre et du Jongleur, narra a estória de um jogral muito pobre, viciado no jogo de dados e visitador assíduo das tavernas, que, depois de morto, teve a alma conduzida ao inferno por um demônio de última categoria (GAILLARD \& RACHMUHL, 1978, pp. 39-44).

A voz do submundo dos jograis aparece, por exemplo, na criação poética dos goliados. Estudantes das Universidades, poetas miseráveis ou simplesmente personagens arredios à discìplina, estes poetas transumantes, vagantes, vagatorum, representaram bem a boemia literária dos séculos XII-XIII.

Pobres natos ou pobres voluntários, os goliardos alardearam a contundência de sua miséria, chamando a si próprios de scolares pauperes e famuli. A origem da palavra utilizada para designar o grupo de poetas blasfemos, segundo certos críticos, pode ser encontrada num vocábulo latino derivado de gula. Os termos Golart, Goliart ou Guliart, empregados correntemente para se referir a eles, possuíam sentido difamatório e injurioso, podendo significar "comilāo" e "beberrão" (DOBIACHE-ROJDESTVENSKY, 1931).

A poesia goliardesca exemplifica um aspecto da reapropriação de elementos da cultura clássica pelos estratos mais baixos dos litterati. No fundo, o conteúdo dos versos dos poetas do submundo dizia respeito a um universo pagão. Muitas Carmina Burana constituem exercícios de retórica, permanecendo desvinculadas das criações culturais dos illiterati.

Não é possível dizer o mesmo dos contos cômicos compostos no século XIII pelos trouvères, para serem recitados pelos jograis do norte da França, da Inglaterra e da Alemanha. Os fabliaux, gênero literário muito pọbre quanto à forma, rima e versificaçăo, são excepcionalmente ricos em imagens do cotidiano das camadas populares urbanas, dando conta de aspectos essenciais do imaginário carnavelesco medieval (JODOGNE, 1975a; BOUTET, 1985).
Nos fabliaux, a boemia e a festividade ocupam espaço significativo, subvertendo a imagem devota e piedosa do cotidiano proposta nos textos de inspiração oficial. É o caso de um monólogo humorístico germânico chamado Der Weinschwelg, isto é, "O Grande Bebedor", em que um ébrio inveterado desenvolve incansavelmente vinte e duas odes para defender com eloqüência as virtudes do vinho, interrompendo a narração apenas para, em repetidos refrōes, descrever como segura o copo e entorna o líquido (MORET, 1939, pp. 254-255). Noutro fabliau germânico, chamado "Os Navegadores de Viena", conta-se a bizarra aventura de um bando de baderneiros que, ao passar a noite numa taverna, bebendo, cantando e farreando, simulam uma viagem marítima ao Oriente, uma espécie de cruzada imaginária e bufa, sendo o vinho o "combustível" escolhido para estimular a peregrinação (MORET, 1939, pp. 235-253).

Num fabliau francês do início do século XIV, de autoria do trouvère Watriquet de Couvin, chamado Des Trois Dames de Paris, o realismo grotesco é ainda mais contundente. Segundo o conto, três esposas de dignos moradores de Paris, no momento de uma missa, dirigiram-se a uma taverna, comendo desmesuradamente e bebendo sem parar durante três dias, até o arrebatamento. Não tendo como pagar, embriagadas e quase sem poder ficar em pê, acabaram sendo enxotadas pelo taverneiro. Passaram a noite desfalecidas na rua, como se estivessem mortas. De manhā, foram enterradas. Logo depois, para o espanto geral do espectadores, levantaram-se das covas, retornando alegremente aos respectivos lares (MÉNARD, 1979, pp. 119-127).

Os estudiosos do conto notaram aspectos importantes do comportamento das pessoas da Idade Média face ao elemento religioso, encontrando na composiçāo do fabliau os vestígios de uma paródia sacra. O historiador Claude Lachet identificou a data do caso narrado com a Festa da Epifania e da Adoração 
dos Reis Magos. A atitude das mulheres, comendo, bebendo, cantando e dançando, dão mostras de uma representação carnavalesca. Esta atitude era comum nas referidas comemorações sacras, imbuídas de espírito carnavalesco. À situação orgiástica dos três dias de desregramento sucede o desfalecimento, e depois, o renascimento para a vida cotidiana. Noutras palavras, como no Carnaval, ofabliau relata uma transgressão, inversāo e reintegração ao mundo da ordem estabelecida (LACHET, 1986, pp. 405-415).

O espaço utópico que se interpōc à cotidianidade ganha destaque noutros textos paródicos. Num trecho expressivo de Aucassin et Nicolette, conto do início do sćculo XIII, o par de amantes que dá nome à estória, numa de suas aventuras, chega na terra de Turelure. O reino de Turelure corresponde a um "mundo às avessas". Entrando no palácio, o jovem Aucassin e a bela Nicolette percebem que o rei está de resguardo, impossibilitado de oferecer combate aos inimigos que atacam sua terra. Enquanto isto, a rainha liclera os guerreiros em batalha. As armas empregadas na luta feroz são maçãs podres, ovos e queijo mole, sendo que no combate é proibido matar ou ferir quem quer que seja (PAUPHILET, 1932, pp. 153-156; MORTARA, 1989; HUNT, 1979, pp. 341346; FERNANDEZ, 1990, pp. 97-105).

Em Audigier, paródia das canções de gesta do final do século XII, o grotesco co absurdo chegam ao ápice. O herói central do conto obsceno e escabroso governa uma terra de nome Cocuce. Neste reino bisonho, os súditos vivem com excrementos até o pescoço. Cavaleiro poltrão e covarde, Audigier perde três combates para uma velha chamada Grinberge, sendo obrigado, em cada uma das derrotas, a beijar-lhe $o$ ânus (JODOGNE, 1960b).

Estes reinos paródicos e carnavalescos constituem locais imaginários inversos ao mundo da cavalaria, em que a covardia e a zombaria são qualificativos para a nobreza; a derrota $e$ a humilhaçāo simbolizam a vitória.
O mundo utópico da inversão, da permissividade, da ilusāo, é resgatado uma vez mais no fabliau do final do século XIII em que é contada a estória de uma viagem imaginária a uma terra paradisíaca, a uma terra das delicias, chamada Cocanha. Segundo o Fabliau de Cocagne, tal local só pode ser atingido em sonho. Lá, quem mais dorme mais tem, os alimentos brotam sem o esforço do trabalho, os rios são de vinho e a chuva é de pudim. Quaresma visita a Terra da Cocanha apenas de vinte em vinte anos e mesmo nestes momentos o jejum nāo é rigoroso. Cocanha é a terra do ócio, da gula e da felicidade. Vive repleta de belas moças, de jovens cheios de cortesia, gozando a eterna juventude (VAANANEN, 1947).

Peter Bruegel transportou para sua pintura este cenário idílico. No quadro Le Pays de Cocagne, pintado em 1567, vemos três homens extasiados, dormindo em baixo de uma mesa forrada dc comida. Perto do primeiro homem há um livro, do segundo, uma lança, e do último, um cambão: um clérigo, um cavaleiro e um camponês. Ao lado, outro cavaleiro contempla tranqüilamente a paisagem, descansando $\mathrm{cm}$ baixo de uma casa em cujo teto existem pratos repletos. No meio do quadro pode-se ver aves e porcos assados à procura de quem possa comê-los. Ao fundo, um homem se esforça para devorar um imenso queijo, entrando dentro dele (BRUEGEL, 1978, prancha 34).

Todas estas obras, imbuídas de uma percepçāo carnavalesca do mundo, repletas de imagens cômicas, licenciosas, grotescas, destruidoras da visão séria e pessimista proposta pela cultura oficial $e$ dominante da Igreja, nāo foram criadas ao mero acaso. Elas integram o sistema mais vasto da cultura cômica popular, estando associadas a uma forma específica de apreensāo do sentido da vida pela massa dos leigos. Paralelamente a elas os leigos desenvolviam toda uma série de práticas que, mesmo não negando de forma cabal $e$ nem se opondo radicalmente às diretrizes da cultura oficial, fundiu-se com ela, dando- 
The contornos diferentes daqueles esperados pelos representantes da religiāo cristã.

Tais práticas consubstanciaram-se, por exemplo, numa série de ritos ou festas populares, reiteradamente condenados pelas autoridades eclesiásticas, mas mesmo assim persistindo ao longo de toda a Idade Média. É o caso da Festa dos Loucos, herdeira das Saturnais Romanas e antecessora do Carnaval moderno, $\mathrm{cm}$ que tomavam parte estudantes e clérigos de baixa cxtraçäo, e que se caracterizava pelo desregramento, subversão e inversão temporária da ordem estabelecida. Os papas dos loucos, bispos dos loucos ou bispos dos inoccntes, no espaço carnavalesco aberto anualmente, tornavam-se os líderes de um mundo ideal e ilusório, o mesmo mundo para o qual os textos citados anteriormente apontam (HEERS, 1987; COX, 1976).

A perspectiva do clérigo Arciprestre de Hita é bem outra. No trecho De la Pelea que Ovo Don Carnal con La Quaresma, adiciona elementos novos ao tema tratado no fabliau, enriquecendo a abordagem do combate bizarro.

Coloca novos personagens em cena. Don Carnal ganha auxiliares, entre os quais Dona Merenda e o Almoço, que se torna o seu emissário. Quaresma nāo fica para trás. Dois amigos aparecem para ajudá-la: Dom Jejum e o Domingo de Ramos.

As hostes beligerantes, da mesma forma, são ampliadas e melhor organizadas. As tropas carnavalescas, por exemplo, são apresentadas segundo uma hierarquia militar, havendo o grupo dos peōes (composto pelas galinhas, perdizes, capões, gordos assados, costelas c pernas de porco), os cscudeiros (entre os quais, queijo frito e vinho tinto), os infançōes (representados pelos faisōes, pavão, gamos, javalis, cervos, lebres, cabras, corças, toucinho) e os cavaleiros (intcgrados pelas carnes de vaca, leitōes e cabritos).

A subjetividadc do poeta ibérico enriqueceu os contornos psicológicos dos protagonistas da con- tenda. Segundo ele, Quaresma aterroriza o mundo por onde passa, banhando as almas com o jejum, a sentença, a obediência e a penitência. Seu poder, retidāo e influência são bem maiores que os do adversário. Apesar das cores vivas, a imagem de Don Carnal no Libro de Buen Amor não é das mais lisonjeiras. É tratado como um nobre bastante poderoso, como um rico imperador. A manifestação deste poder, contudo, conduz ao mal, e não ao bem. A atuação de Don Carnal causa transtorno, prejudicando ó mundo. Ele é obstinado no erro. Além do mais, é soberbo e orgulhoso, guloso e luxurioso, desenfreado e invejoso, mentiroso e avaro.

Quaresma, irritada com a extravagância do desenfreado, desafia-o para um combate. Ao receber a mensagem, Don Carnal manda avisar os aliados, preparando-se para a defesa, mas não responde formalmente ao desafio. Pelo contrário, movido pelo impulso natural, cai na farra, na bebedeira e na comilança. Quando a "Justiceira do Mar" chega ao castelo do "celerado", encontra-o em pleno sono. Don Carnal e os guerreiros convocados para auxiliá-lo sofrem uma humilhante derrota: as sardinhas machucam as galinhas, os caçōes matam as perdizes e castram os capōes; camarōes, arenques e baleias desbaratam os cavaleiros e os peōes. Carnal, muito ferido, é levado para a prisāo, ficando obrigado a confessar e fazer penitência para expiar os pecados.

Com Don Carnal na masmorra, Quaresma domina a terra, observando os pecadores, corrigindo-os, exigindo-Ihes confissāo, contrição e infligindo-lhes penitência. Esvazia os potes, jarros e barris, por serem todos eles recipientes de bebida. Manda lavar grelhas e espetos. Convoca todos os cristāos para ir assistir missa. Quanto ao "grande pecador", é entregue a um frade. Arrependido, fraco, choroso e contrito, submete-se à penitência, comendo apenas uma vez por dia:

Desque el buen frayre ovo á Carnal confesado, Diól esta penitencia: que por tanto pecado, 
Comiese cada día un manjar señalado

E que mas non comiese é seríe perdonado (Estrofe 1162)

$\mathrm{Na}$ sétima semana de reclusão, quando Don Jejum e o Domingo de Ramos levavam o prisioneiro para assistir missa, Dom Carnal aproveitou a oportunidade e escapou, pedindo ajuda aos judeus. Novaménte livre, reagrupou os amigos c aliados: cabras, cabritos, carnciros, ovclhas, touros e bezerros, recrutados pelo Almoço, socorreram-no. Juntando as forças com Dona Merenda, partiu ao encontro da "vil e magra" Quaresma. Os peixes haviam retornado ao mar, nāo podendo socorrê-la. Fraca e inerme, a terrível justiccira teve de abandonar a terra, partindo $\mathrm{em}$ peregrinaçāo rumo a Santiago de Compostela.

Os dois textos, como podemos notar em sua estrutura narrativa interna, apresentam em grandes linhas uma alegoria do período quaresmal. Descrevem a sua chegada, o combate simbólico contra o espírito carnavalesco e a mudança de comportamento, em decorrência da abstinência via estômago. $O$ resultado nāo podia ser outro. Apesar da força, Quaresma anualmente ć vencida, sendo obrigada a sair de cena.

Passado o período da Quaresma, um estranho e curioso ritual burlesco era praticado em certos reinos medievais. No dia da Páscoa, os padres rezavam uma missa em tom jocoso, estimulando o riso e a farra dos fiéis, em que era exteriorizada ao mesmo tempo a alegria pela ascensão de Cristo e um sentimento de alívio em virtude da passagem de uma fase de angústia e mortificaçāo. Este "Riso Pascal" nos dá uma boa idéia da alternância das emoçōes e dos comporta. mentos permitidos (ou pelo menos tolerados) pcla instituiçāo religiosa (REINACH, 1912, pp. 128-129; PROPP, s/d, p. 96).

A leitura do fabliau e do trecho do Libro de Buen Amor revelam bem a referida alternância. Mas a forma e o tom presentes em cada um dos textos demonstra a existência de posturas divergentes no tra- tamento do tema. Apcsar do assunto ser idêntico, a abordagem e o desenvolvimento sāo opostos. Nesta oposição, segundo pensamos, reside parte da ambivalência da cultura cômica popular.

Na fabliau La Bataille de Caresme et de Charnage, todo o combate descrito advém de um desentendimento inicial que opōe os dois principais personagens da alegoria. Logo no início do poema, o escritor afirma que Caresme ofendeu Charnage. Ambos cstavam na corte do Rei, em Paris. O motivo da desavença e da ofensa nāo chega a ser mencionado. O jogral limita-se a afirmar que houve um conflito armado e que Charnage levou a pior, sendo derrotado junto com os seus aliados. A grande batalha narrada subseqüentemente corresponde, portanto, a uma revanche do perdedor inicial. Somente nestes primeiros versos há alusão a uma primeira derrota do Carnaval:

\section{Lors fu Charnage mis arriers \\ Por la bone plais raiere \\ Et por les autres poissons fres \\ Dont lien fet a ces cors granz mes \\ (vv. 85-88)}

Enquanto no fabliau a ênfase recai no segundo confronto e na vitória das hostes carnavalescas, a perspectiva de Arciprestre de Hita é completamente inversa. Praticamente todos os versos do Libro de Buen Amor dedicados à contenda correspondem aos quatro versos do fabliau mencionados acima.

A descrição do desafio lançado pela "Justiccira do Mar", dos excessos mundanos de Don Carnal, da comilança e da embriaguez consumiram centenas de versos. A atenção especial para com o primeiro combate, no qual o "desregrado" sucumbiu, assim como à prisão $e$ penitência (tratados apenas no Libro), basicamente completam a narração. Nos versos finais, quando o derrotado parte à revanche, vence sem luta, pois os defensores da terrível algoz nāo estavam presentes para defendê-la. Desta maneira, pode-se dizer 
que toda a matéria tratada no Libro, quando comparada com a do fabliau, reforça a idéia da derrota do Carnaval, apresentando o resultado do confronto final como uma fatalidade.

Há alguns aspectos interessantes relacionados ao resultado do embate. No fabliau, a ajuda de Noel (Natal) é decisiva para a vitória de Charnage. No Libro, Don Carnal é ajudado por Dona Merenda e o Almoço. Quem primeiro lhe presta auxílio, entretanto, são os judeus, de quem rccebe um cavalo para retornar à Terra.

Afinal, qual o significado da vitória do Carnaval?

Quando o autor do fabliau introduz Natal $\mathrm{em}$ sua alegoria, remete os leitores ou ouvintes para um período de alegria e descontração, festejado na Idade Média com gestos e atos tipicamente carnavalescos.

Por ocasiāo do Natal ocorria, como lembra Jacques Heers, uma série de "festas de inverno", como a de Săo Nicolau, comemorada no dia 6 de dezembro; a de Santo Estevão, em 26 de dezembro; de Săo Joāo Evangelista, no dia 27 de dezembro; a dos Santos Inocentes, em 28 de dezcmbro; a da Circuncisão, em $1^{\text {1" }}$ de janeiro; a da Epifania, em 6 de janeiro; a da Oitava da Epifania, no dia 14 de janeiro. Nestas festas, o riso, a extravagância, a licenciosidade, a comilança e a bebedeira ganhavam as igrejas e as ruas (HEERS, 1987, pp. 83-85).

Pela ótica de Arciprestre de Hita, são os judeus que ajudam Don Carnal. Ora, sabe-se bem qual a imagem do judeu no Ocidente cristāo. Ao lado dos leprosos, dos mendigos, dos loucos, era tido como um pária da sociedade. Como diz Jacques Le Goff, "ele é,

\section{Bibliografia}

AlCASSINo E NICOLETA. Trad. Marcela Mortara. Rio de Janciro, Francisco Alves, 1989.

ARCIPRESTE DE HITA. Libro de Bucn Amor, Ed. Julio C. y Frauca. Madri, Espasa-Calpe, 1951, vol. II. antes de tudo, o homem do erro, da falsidade religiosa". Sobre o judeu recai uma espécie de culpa ancestral pela morte de Cristo. No imaginário coletivo dos cristãos, é visto como deicida (LE GOFF, s/d, p. 167). A associação entre Don Carnal e estes "impuros", portanto, indica bem a posição de Arciprestre em relação ao Carnaval.

Os críticos literários costumam lembrar as dificuldades de interpretação e a ambigüidade do Libro de Buen Amor. A inserção de imagens grotescas, de ccnas caricaturadas, a eleição de buen amor como tema principal e o tom irônico com que este é tratado poderiam remeter o leitor tanto para o sentido profano da carne quanto para o questionamento da vida mundana (SCHOLBERG, 1971, p. 172).

- Em se tratando do trecho aqui examinado, todavia, não há ambigüidade. Apesar do tratamento paródico do estilo épico, o objetivo do clérigo é evidente: escreveu para condenar o Carnaval. Isto reforça o argumento de Mikhail Bakhtin em favor do caráter circular nas relações entre a cultura popular e a cultura oficial, da mescla e fusāo entre diferentes visōes de mundo. Terminaremos este trabalho citando algumas palavras do crítico russo, que em nosso entender sintetizam bem o que a leitura de ambos os textos estudados podem proporcionar:

Os homens da Idade Média participavam igualmente de duas vidas: a oficial e a carnavalesca, e de dois aspectos do mundo: um piedoso e sério, o outro cômico ... No entanto ... uma fronteira interna delimita os dois aspectos: mesmo existindo lado a lado, eles nāo confundem, não se misturam. (BAKHTIN, 1987, p. 83).

BAKHTIN, Mikhail. A Cultura Popular na ldade Mćdia $c$ no Renascimento. Trad. Yara F. Vieira. São Paulo, Hucitec. Ed. UnB, 1987.

BAROJA, Julio C. Lc Carnaval. Trad. Syivie Sesé-Léger. Pa- 
ris, Gallimard, 1979.

LA BATAILLE de Caresme et de Charnage. Éd. Gregoire Lozinski. Paris, Ancienne Honore-Champion, 1933.

BOUTET, Dominique. Les Fabliaux. Paris, PUF, 1985.

BRION, Marcel. Breughel. Paris, Éd. d'Histoire el d'Art/Libr. Plon, 1936.

BRUEghel, Pieter. Col. Mcstres da Pintura. São Paulo, Ed. Abril, 1978.

CHEVAlier, J. \& GHEERBRANT, A. Dictionnaire des Symboles. Paris, Seghers/Jupiter, 1974, vol. 4.

CIRLOT, J. E. Dicionário de Símbolos. Trad. Eduardo F. Frias. São Paulo, Mornes, 1984.

COX, Harvey. A Festa dos Foliócs. Petrópolis, Vozes, 1976.

DOBIACHE-ROJDESTVENSKY, Olga. Les Podsics des Goliards. Paris, Rieder, 1931.

FARAL, Edmond. Les Jonglcurs en France au Moycn Age. Genebra, Slalkine, reed. 1987.

FERGUSON, George. Signs and Simbols in Christian Art. New York, Oxford University Press, 1961.

FERNANDES, F. Carmona, "Parodic el Humour dans le Roman en Vers de la Première Moitié du XIII Siècle: Allusion et Tradition dans Aucassin el Nicolette". In: Le Rire au Moyen Age dans la Litcraturc et dans les Arts. Boudeaux, Presses Universitaires de Bourdeaux/CNRS, 1990.

FRANCO Jr., Hilário. As Utopias Medicvais. São Paulo, Brasiliense, 1992.

GAIGNEBET, C. "Le Combat de Carnaval et de Carême". Annales ESC, 27-2, 1972, pp. 313-345.

GAILLARD, Pol \& RACHMUHL, F. Les Fabliaux du Moyen Agc. Paris, Hatier, 1978.

HEERS, Jacques. Festas de Loucos a Carnavais. Trad. Carlos Porto. Lisboa, Publicações Don Quixote, 1987.

HUNT, Tony. "La Parodie Médievale: Le Cas d'Aucassin el Nicolette". Romania, Tome 100, n.3, 1979, pp.341346.

JODOGNE, Omer. Lc Fabliau. Brepols, Turnhout, 1975.
“Audigier et la Chanson de Geste". Le Moyen Agc, Tome LXVI, n.4, 1960, pp. 495-526.

KUNSTAMANN, Pierre (Éd). Vierge et Merveille: Les Miracles de Notre Dame Narratifs Au Moyen Age. Paris, Union Générale d'éditions, 1981.

LACHET, Claude. "Composition et Signification des Trois Dames de Paris". Le Moyen Age, Tome XLII, n. 3-4, 1986, pp. 405-415.

LE GOFF, Jacques. Para um Novo Conceito de Idade Média. Trad. Maria Helena C. Dias. Lisboa, Estampa, 1980.

. O Maravilhoso c o Quotidiano no Ocidente Mc. dieval. Lishoa, Edições 70, s/d.

MÉNARD, Philippe (Éd). Fabliaux Français du Moyen Age. Genebra, Droz, 1979.

MORET, André (Éd). Poèmes et Fablcaux du Moyen Age Allemand. Paris, Aubier-Montaigne, 1939.

PROPP, Vladimir. “O Riso Ritual no Folclore”. In: Édipo d Luz do Folclore, Lisbon, Vega, s/d, pp. 69-113.

PAUPHILET, Albert. Contcs du Jonglcur. Paris, H. Piazza, 1932.

REAU, Louis. Iconographic de I'Art Chrétien, Tome II-2. Paris, PUF, 1957.

REINACH, Salomon. "Le Rire Rituel". In: Cultes, Mythes et Religions. Paris, Ernest Leroux, 1912. Tome IV.

SCHOLBERG, Kenneth. Satira y Invectiva en la Espanha Medicval. Madri, Gredos, 1971.

VAANANEN, Veikko (Ed). "Le Fabliau de Cocagne". Neuphilologische Mitteilungen, n.48, 1947, pp. 3.36.

VACANDARD, E. "Carême". Dictionnairc de Théologic Catholique. Paris, Letouzey el Ané, 1910. Tome II, pp. 1724-1750.

"Carême". In: Dicrionnairc d'Archcologic Chréticnne el de Liturgie. Paris, Letouzey el Ané, 1925. Tome II-2 parlie, pp. 2152-21660.

ZUMTHOR, Paul. A Letra c a Voz. Trad. Amalio Pinheiro/ Jerusa P. Ferreira. Sảo Paulo, Cia. das Letras, 1993.

Endereço do Autor: Departamento de História - UFRGS - Av. Bento Gonçalves, 9.500 - CEP 91540.000 Potto Alegre - Rio

Grande do Sul - Brasil - FAX (051) 336-4500 